\title{
MULTIDISCIPLINARY TEACHING CONFORMATION OF A HUMANISTIC CENTRE AND THE USE OF AUDIOVISUAL NARRATIVES AS A DIDACTIC RESOURCE
}

\author{
M. Ramírez Cordero \\ Lecturer of the Centre for General Studies at the National University of Costa Rica. (COSTA \\ RICA)
}

\begin{abstract}
The aim of this work was to determine the use of audiovisual narratives (NAV) as a didactic tool by teachers of the Centre for General Studies (CEG) of the National University (UNA), Costa Rica; as well as the courses and disciplinary areas that use them the most, and to know their origin. Methodology. In order to elucidate the way in which the AVNs are used in the CEG courses the syllabus of the 76 courses that were taught during the first semester of 2014 were analyzed. Results and conclusions. Half of the teachers of the CEG use AVNs (documentary and fiction). Mainly thematic use of NAV (pretext). Areas that use AVN most (Science and Technology, Philosophy and Literature) and the most resorted AVN are those originated in the United States.

This work, of a qualitative nature, emerges from the author's teaching practice as a professor of film appreciation in the CEG, which is the pedagogical and multidisciplinary nucleus of the university, where all the new students must go through, indistinctly of the course they enroll at the university.

Academic authorities at the CEG are planning to move from the current multidisciplinary composition of the Centre towards interdisciplinarity, as a preliminary step to a transdisciplinary way of approaching the praxis that governs the CEG (Curriculum Redesign, 2008). This is how this study on the teachers' common practices at the Centre begins, regarding the use of NAV in the light of the courses' syllabus given during the first semester of 2014.
\end{abstract}

Keywords: Audiovisual narrative; general studies; Multidisciplinary; Interdisciplinary; Transdisciplinary education.

\section{INTRODUCTION}

This paper arises from the educational practice of the author as a lecturer of film appreciation in the CEG, which is the pedagogical and multidisciplinary nucleus, through which all the students of first entrance to the Costa Rican National University (UNA) must pass, regardless of the career they enrol.

In this context, the Audiovisual Narratives (NAVs) play a fundamental role because of the strong exposure of students to these; therefore, it is almost imperative to analyze the practices that are carried out in all disciplinary areas that use NAV as a didactic resource.

The institution gives the technological resources but in general, none reflexion over its use. It is not intended to suggest with this work suggest that the teachers beyond the film appreciation courses become experts or movie critics, nor that the use of the AVN moves away from its practical utility (thematic use) for each of the disciplines or courses, but to call to call the attention on which the AVNs for its capacity of penetration and influence in the spectator, must be treated in an integral manner; that to say, from its context and to the formal and expressive aspects and, to differentiate them, from the pure entertainment, with respect of the creations that express a criticism or a feeling as already recognized en the 1930s in the United Kingdom when it was urged to employ the film in a manner similar to the treatment given to literature well.

Definitely, to achieve that the student (and of course the teacher), acquire any degree of judgment which allows them to develop a critic and a selective eye at the time they face the enormous audiovisual offer out of the classroom.

In the CEG, the academic authorities are planning to move from the multidisciplinary composition of the Center towards interdisciplinarity, as a preliminary step to a transdisciplinary way of approaching the praxis, that governs the CEG as reflected in the Curricular redesign [1] in the next five years. 
This study aims to contribute to an integral approach, not only on the part of each one of the areas or disciplines in which it is used, but also, generating the possibility that can be applied in an interdisciplinary and inter-knowledge area.

The AVN that comprise the different forms and genres that involve the moving image, which are a powerful medium, not only of entertainment, in tis more well-known and commercial mode, if not as a educative resource in its "pure" variant; that is, didactic, which is that audiovisual intended with the finality to be used in the class room and that requires a high degree of knowledge to its production.

Likewise happens with the movie that is produced with strictly commercial purposes or of the expressive kind or art cinema. The first one is of easy and immediate of access and the second less, though it is possible to find works with those characteristics in some commercial circuits or of art circuits.

The current practice in the different educational ambiances is to use the AVN as a pretext to reinforce contents or substitute readings that the students are not ready to do. It would be said that is an option per se from the teacher, diluting with this the total improvement that would be obtained from this resource.

It is important to highlight and, although there is a great controversy about the best approach to use of the AVN in the classroom, if in it is emphasized in its textual value or because its formal and technical aspects, it is important to bring up how from the beginnings of the 20th century when it was glimpsed the potential of the cinema in its more common variants (as a textual or contextual and artistic resource), Either as a pretext or addressing its formal and technical aspects (camera, acting, editing, etc.), it should not be lost sight of that, except specific film appreciation courses, in the rest of the courses, the NAV that are used must necessarily relate the topic treated in class with the main theme of the same. However, it is important that the teacher have general criteria about what implies in contextual terms.

\section{METHODOLOGY}

This work is a case study, whose main objective is, both quantitatively and qualitatively, to elucidate the form that the use of NAV in the teaching practice of the CEG acquires according to its nature and objectives, by analyzing the programs of each one of the teachers of the four areas of knowledge that comprise it (Art, Social Sciences, Science and Technology and Philosophy and Literature).

The course programs were used because they are the contract that the institution considers as the only form of student and teacher relationship and in which are clearly expressed, both the methodological proposal of the UNA in general and the CEG in particular, such as contents or topics, evaluation strategies and schedule of activities that each teacher considers for their courses.

For the collection of data (course programs), the archives of the Academic Vicedeanery of the CEG were used, in which the programs must be deposited prior to the beginning of the courses of the corresponding year.

We have read the programs and obtained the required information, separating it in graphs to be able to value in quantity and percentage the different uses of the NAV in the CEG.

\section{RESULTS}

\subsection{Mainly thematic use of AVN}

The use of VNS is an important alternative in the face of the difficulty of using the book, which has been relegated nowadays [2] due to the almost null reading habits of students, rejecting this practice, a rejection that will be extended in time and will extend to practically every written word, as expressed very well Amar [3], becoming a kind of "agraphy", resulting in an absolute empire of the image over the written text, which according to Arana [4] marks a difference between the students' receptivity to the audiovisual in relation to reading.

In spite of this protagonism of the moving image over the written text, a certain parallelism is symptomatic in the use that teachers make of the NAV, as substitute of the book, without realizing that both are different ways to make an approach, which demonstrates that in the end, there are traditional practices difficult to eradicate, as Beltrán [5] says when referring to a good part of the teaching staff 
that " continues to stick to blackboard and chalk" and not necessarily because it is with bad faith or for lack of care, simply because it is necessary to assume that it is essential to train teachers in the different aspects of the AVN

\subsection{Half of the CEG teachers uses NAV}

Next, the frequency and use and origin of the NAV employed in the courses of the CEG during the first semester of the year 2014 are analyzed. The analysis of the programs allowed us to see the type of NAV used, if documentary or fiction, and if the latter was of long or short footage

Regarding the use made of this resource, the difference between one group and another is minimal; in the analysis of the programs the difference could be noticed when it came to the NAV in the specific courses of Film appreciation and those of the other disciplines. In the case of film appreciation courses in which, due to their nature, the focus is necessarily different, emphasizing the richness of each work itself and its contribution, both in form and in content, "narrative and story " [6].

Total courses of the CEG

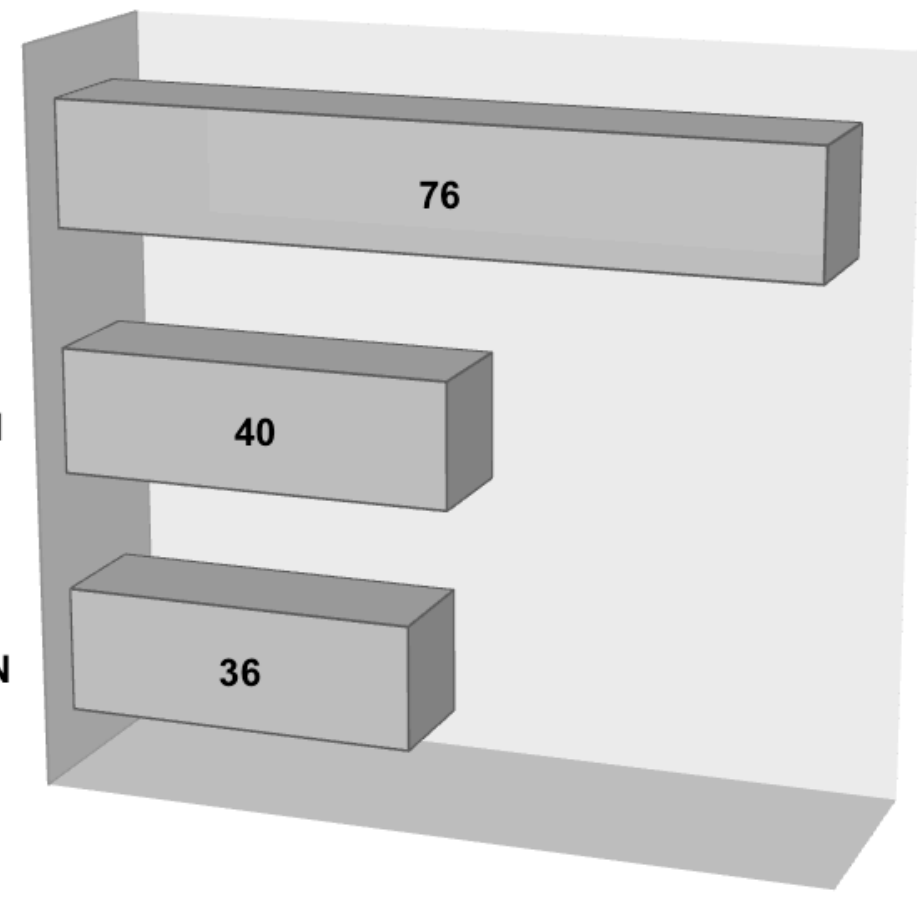

Fig. 1 Number of courses in which AVNs are used

\subsection{Areas that more AVN use}

It is also noticeable that in the courses of the Art Area the use of the AVN is not very extended, unlike the courses of Science and Technology Area that use this in the majority, whereas in the courses that use them in the Area of Social Sciences was smaller, even "surpassed" by the Area of Philosophy and Literature and by a great margin.

However, it is necessary to clarify that the genre of NAV that is most used in the Area of Science and Technology is the documentary, 33 productions of different footage, which does not mean that fiction material cannot be used to work the courses as demonstrated by Beltrán [5] on the use of fiction films for math courses. Again, it is possible to observe that the Area of Social Sciences has a lag that does not cease to attract attention because much material in both modalities, fiction and documentary, can be easily exploitable in this area. 


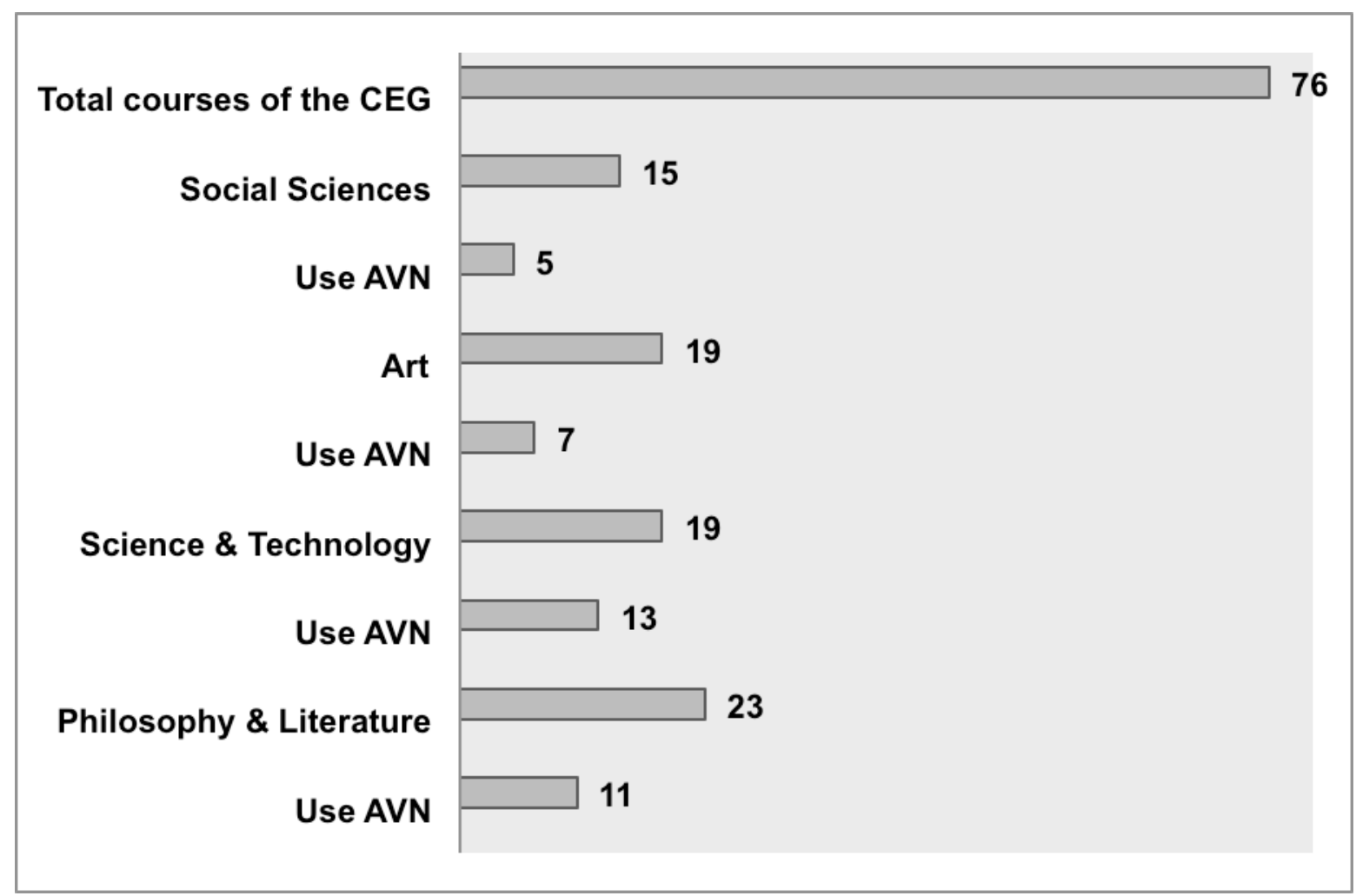

Fig. 2 Courses by area that use AVN

\subsection{The long feature film are the most used}

Regarding the use of long and short feature films, the Area of Art is the one that uses these the most, however, the courses of film appreciation are mainly the ones that resort to this material. It is important to highlight the use of short feature films, since this modality receives little to no attention, in spite of the fact that there is a wide offer of both Costa Rican and foreign production.

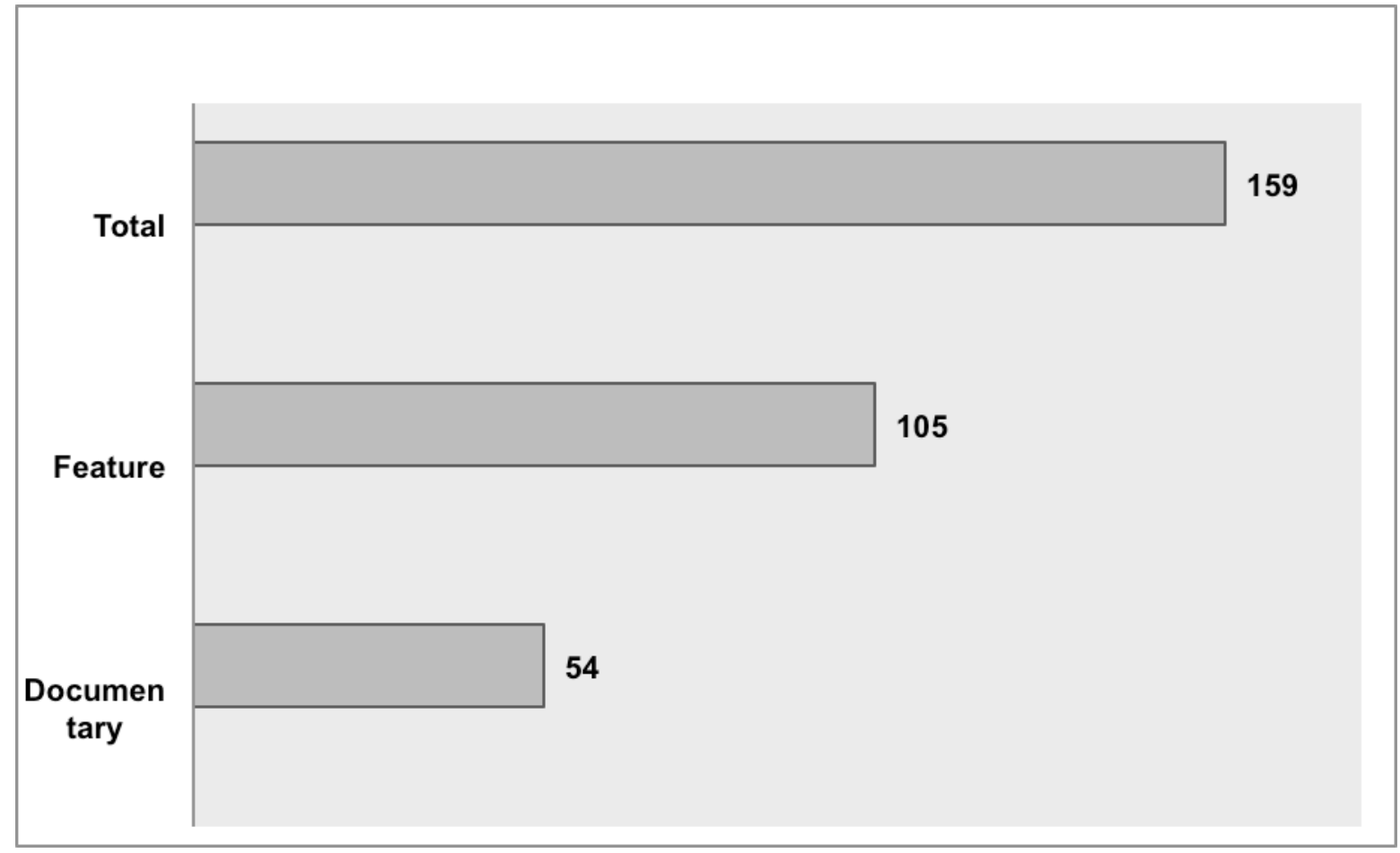

Fig. 3 Total of AVN by genre 


\subsection{The most frequently used NAV are those that originate in the United States}

Another outstanding aspect, although not surprising, is confirming the strong presence of movies coming from the US industry (with $22 \%$ of the screened titles), which duplicates two of the more traditional cinematographies of Latin America as are those of Argentina and Mexico (that represent only $6 \%$ and $4 \%$ respectively). Another symptomatic aspect is the lack of cinematographies from other continents: China, India, Iran, Turkey, Israel, Russia (or the ex USSR), Australia, Denmark, Sweden, France, Italy, just to mention traditional cinematographies, although some of these appear in the list (22 in total), but with only one or two mentions.

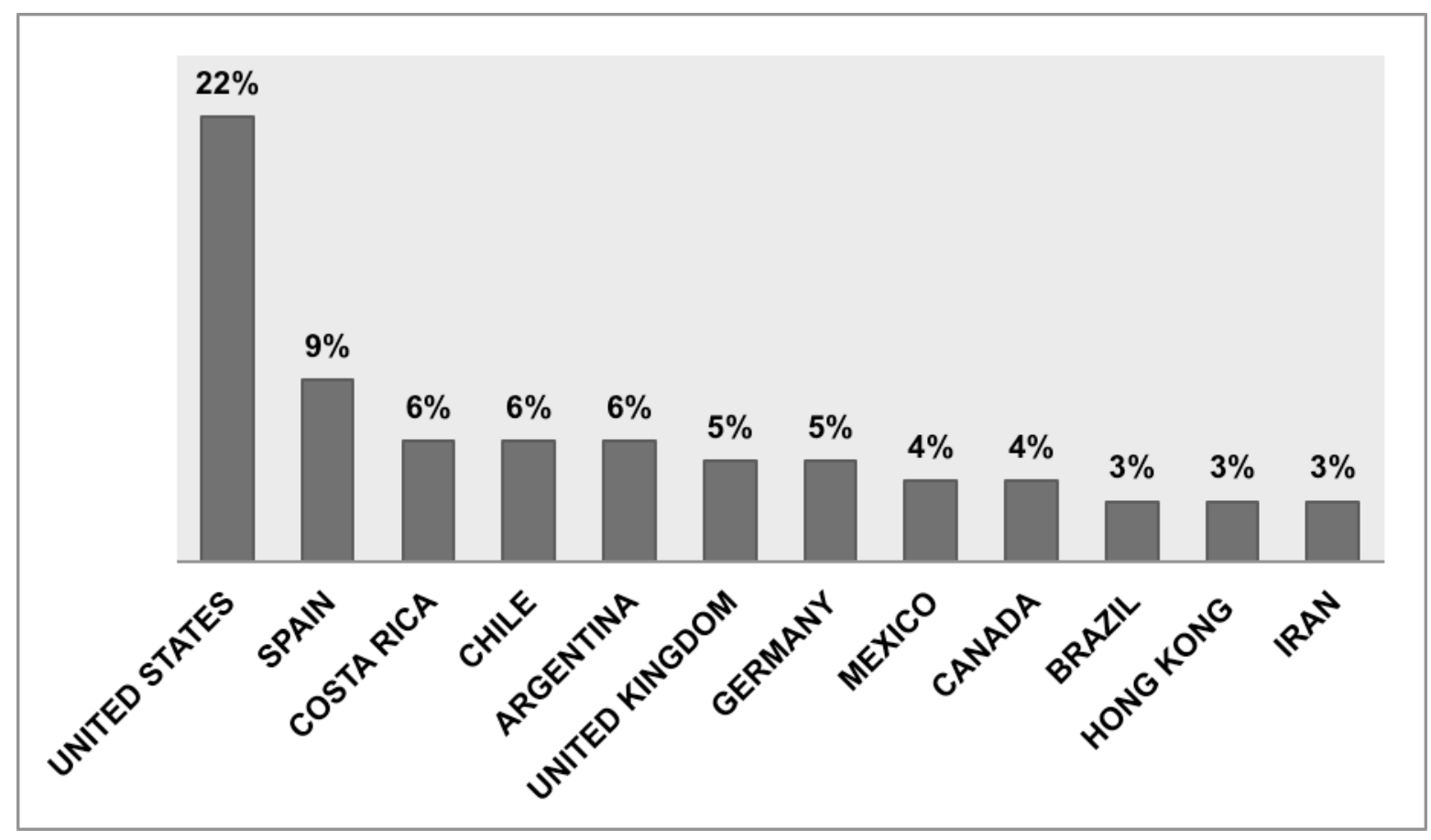

Fig. 4 Origin of long feature films

\section{CONCLUSIONS}

It is concluded that NAV can be used in different disciplinary areas demonstrating its enormous potential and ductility as is the case of the use of the type of NAV previously proposed for classes of Mathematics developed by Beltrán [5] in his thesis dedicated to demonstrate that it is possible to use feature films and television series for this purpose and for teachers this may well become an opportunity to penetrate other areas of knowledge, going even further, including the possibility of doing so in formal and aesthetic aspects (not only thematic) of the AVNs.

The CEG, in agreement with all been exposed before respect to the employment that is done with the AVN in the educational ambiance, it is not exempt to fall in this practices. While is true that trough the analysis of the programs of the courses it can be noted the difference when it involves the AVN in the specific courses of film appreciation, in which, by its nature, the approach is different, neither can it be inferred that these courses are for aesthetics and film analysis in the strict sense, because the objectives of the courses, more than be centered in aspects of that kind, is to do it with emphasis in the richness of each film itself and its contribution, certainly, both in the artistic and as in what expresses.

It is unquestionable that before the intensive and extensive use of NAV, it is necessary to contemplate the training in film analysis for the teachers, not at the level of pretending to turn them into film critics, aspect in which there is still much to analyse, but rather as an approach to a more comprehensive form of analysis [7].

Even though they are still somewhat isolated, some interesting actions have also been promoted from public institutions. The Institute of Educational Technologies (IET) of the Spanish Ministry of Education has been practicing for almost a decade the distance-learning course "Cinema as a didactic resource", 
in which hundreds of teachers have specialized in the use of cinema in the classroom. Also some autonomous communities have implemented similar courses in which cinema, television, radio, press, Internet, etc. are being studied [8].

UNESCO has also played an important role in promoting the use of AVNs in education with documents such as the 1964 Screen Education Teaching Critical Approach to Film and Television, which followed up the International Film and Television Teaching Encounter (Oslo, Norway In 1962) [9]. Although the idea of a kind of courses of appreciation of cinema and its inclusion in the school curriculum persists, it is rather more than that, the restructuring of the teacher and its traditional work and assume a more complex vision and practice, as can be the interdisciplinary modality that implies certain difficulties because it requires from the teacher to acquire new knowledge, representations and attitudes [10].

It would also be important to address the use of American cinema in its majority as an exercise in the diversification of the audiovisual offer in the classrooms and that, in turn, allows to recover the own cultural expression as it said the former minister of culture of France Jack Lang In the Mondiacult Conference in 1982 in Mexico [11] and also expresses Bolas [12] about cinema that reveals the soul of a nation: " the lifestyle, the consciousness, the attitudes. "

This requires, obviously, a change in the mentality of teachers, who are not exempt from Hollywood influence, but this change can only take place through the training to appreciate the NAV in any of its variants, both in aspects of context (who, for what and where it occurs), as well as formal (visual and auditory) and expressive (what) and an approach to alternative cinematographies, understood as NAV originating outside the Hollywood sphere or any other but whose interest is strictly commercial: " From this ethical perspective it is obvious that a significant learning must start that in addition suppose the climbing of the first step of a gnoseological and moral staircase. [7] "

Obviously, it is not a change that is going to happen overnight and has to be gradual, so that both teachers and students discover the "mysteries" that surround these "other" cinematographies, far removed from the way Hollywood, which rather than proceed in its intrinsic way from the film mecca itself, are based on instances such as the United States Department of Commerce that gives directives to the Congress, both of an economic and ideological order that: they question the claims of that Hollywood is a totally free enterprise and that the United States Government is not interested in combining trade with cultural change [11]. What, in turn, is precisely exposed by Mingant [13], when he reveals that the majors combine economic strategies of coercion with strategies in the field of seduction. Thus, a narrative full of stereotypes, which although some may be edifying, do not stop hiding a way to do, therefore, to manipulate a captive spectator.

\section{REFERENCES}

[1] Centre of General Studies (CEG), "Curriculum redesign proposal of humanistic training" [Propuesta de rediseño curricular de formación humanística]. Heredia/Costa Rica: CEG-UNA, 2008.

[2] A. Pereira, L. F. Valero, "Cinema in social education studies as a catalyst for the construction of the European space of higher education," ["Cine en los estudios de educación social como catalizador para la construcción del espacio europeo de educación superior,"] Enseñanza Teach, vol. 28, no.1, pp.-pp.115-138, 2010. https://dialnet.uniroja.es/servlet/articulo?codigo=3332731

[3] V. Amar, "Cinema in the crossroads of the education and kowledge," [El cine en la encrucijada de la educación y el conocimiento], Enl@ce Rev Venez Inf Tecnol y Conoc, vol. 6, no. 2, pp.-pp., 131140, 2009. Retrieved from URL. https://dialnet.unirioja.es/servlet/articulo?codigo=3003188

[4] R. Arana, $\mathrm{M}^{\mathrm{a}}$ A Echevarría, H. Echevarría, Rigths to the cinema: a methodological proposal. [Derechos al cine: una propuesta metodológica]. Bilbao: Bakeaz; 2008.

[5] P. Beltrán, "Series and feature films as a didactic resource in mathematics in secondary education" [Series y largometrajes como recurso didáctico en matemáticas en educación secundaria,"] [Tesis doctoral]. Madrid: UNED, Facultad de Educación; 2005. Retrieved from URL. http://espacio.uned.es/fez/view/tesisuned:Educacion-Pbeltran

[6] A. Gaudreault; F. Jost, The Cinematographic Story [El relato cinematográfico. Cine y narratología]. Barcelona: Ediciones Paidós Ibérica S.A., 1995.

[7] R. Rojano, "Cinema and Education: The didactic use of cinema in the Faculty of Education Sciences of the University of Malaga" ["Cine y Educación: El uso didáctico del cine en la Facultad de 
Ciencias de la Educación de la Universidad de Málaga,"] [Tesis doctoral]. Málaga: Universidad de Málaga, Facultad de Ciencias de la Educación; 2015. Retrieved from URL. http://www.tdx.cat/handle/10803/311449?locale-attribute=en

[8] D. Aparicio, "The use of cinema as didactic resource. An experience of Media Education from the Institute of Educational Technologies" ["El uso del cine como recurso didáctico. Una experiencia de Educación Mediática desde el Instituto de Tecnologías Educativas,"], vol. no. pp.-pp., 1-10, 2012? Retrieved from URL. http://www.educacionmediatica.es/comunicaciones/Eje 2/Daniel Aparicio.pdf

[9] A. Hodgkinson, "Screen education Teaching a critical approach to cinema and television," Paris: UNESCO, 1964. Retrieved from URL. http://unesdoc.unesco.org/images/0005/000595/059573eo.pdf

[10] L. D' Hainaut, Interdisciplinarity in general education [La interdisciplinariedad en la enseñanza general]. París: UNESCO; 1985.

[11] T. Miller, N.Govil, J. McMurria, R.Maxwell, Global Hollywood [El nuevo Hollywood. Del imperialismo cultural a las leyes del marketing]. Barcelona: Ediciones Paidós Ibérica, S. A., 2005.

[12] T. Bolas, Screen Education. Chicago: The University of Chicago Press; 2009.

[13] N. Mingant, Hollywood to conquer the world. Markets, Strategies, Influences [Hollywood à la conquête du monde. Marchés, stratégies, influences]. Paris: CNRS Édtions, 2016. 